\title{
Rituximab is more effective than second anti-TNF therapy in rheumatoid arthritis patients and previous TNF $\alpha$ blocker failure
}

This article was published in the following Dove Press journal:

Biologics:Targets and Therapy

29 June 2012

Number of times this article has been viewed

Joern Kekow'

Ulf Mueller-Ladner ${ }^{2}$

Hendrik Schulze-Koops ${ }^{3}$

'Clinic of Rheumatology and Orthopedics, Otto-von-Guericke University of Magdeburg, Vogelsang-Gommern; ${ }^{2}$ Department of Rheumatology and Clinical Immunology, Kerckhoff Clinic, Bad Nauheim; ${ }^{3}$ Division of Rheumatology, University of Munich, Munich, Germany
Correspondence: Joern Kekow Clinic of Rheumatology and Orthopedics, Otto-von-Guericke University of Magdeburg, Sophie-v-Boetticher-Str. I, 39245 Vogelsang-Gommern, Germany Tel +493920067300

Fax +4939200673II

Email joern.kekow@med.ovgu.de
Purpose: To assess the efficacy of one course of rituximab (two 1-g doses) compared to an alternative tumor necrosis factor- $\alpha(\mathrm{TNF} \alpha)$ blocker in rheumatoid arthritis patients who had experienced one previous TNF $\alpha$ blocker failure (eg, etanercept, adalimumab, or infliximab).

Patients and methods: The efficacy of both treatments was studied in this retrospective, multicenter, noninterventional cohort study with 196 patients. All patients had active rheumatoid arthritis defined by a Disease Activity Score-28 of $\geq 3.2$ despite having TNF $\alpha$ blocker therapy, and were followed over 6.6 months on average after switching to rituximab versus a second TNF $\alpha$ blocker (ie, switching to etanercept, adalimumab, or infliximab) at baseline.

Results: At baseline, both cohorts showed similar demographic and disease-related characteristics (including Disease Activity Score-28). At the end of observation, mean Disease Activity Score-28 was significantly lower after treatment with rituximab than with a second TNF $\alpha$ blocker $(-1.64$ [95\% confidence interval: $-1.92 ;-1.36$ ] versus -1.19 [95\% confidence interval: $-1.42 ;-0.96$ ], $P=0.013)$. This difference between the two groups was even more pronounced when patients were seropositive for rheumatoid factor $(-1.66$ versus $-1.17, P=0.018)$ and anti-cyclic citrullinated peptide antibodies $(-1.75$ versus $-1.06, P=0.002)$. More rituximab-treated patients achieved good European League Against Rheumatism response than TNF $\alpha$ blocker-treated patients ( $30 \%$ versus $15 \%$ ), and less patients were nonresponders ( $22 \%$ versus $35 \%$ ) according to European League Against Rheumatism criteria ( $P=0.022$, chi-squared test).

Conclusion: Treatment with rituximab was more effective than a second TNF $\alpha$ blocker therapy in rheumatoid arthritis patients after failure of the first TNF $\alpha$ blocker. It was found that anti-cyclic citrullinated peptide antibodies may be a useful predictive biomarker for response to rituximab in patients with $\mathrm{TNF} \alpha$ blocker treatment failure.

Keywords: rheumatoid arthritis, rituximab, anti-cyclic citrullinated peptide antibodies, rheumatoid factor

\section{Introduction}

Rheumatoid arthritis (RA) is a chronic inflammatory systemic disease, preferably affecting the joints, and seriously impairing quality of life of RA patients. ${ }^{1}$ The ultimate therapeutic goal in treatment of RA is remission, or at least low disease activity, which frequently requires combination therapies of different drugs or sequential adjustment of the treatment strategy. Several treatment options are available, ranging from symptom relief through nonsteroidal anti-inflammatory drugs to disease-modifying antirheumatic drugs (DMARDs) and biologics (antitumor necrosis factor- $\alpha$ [antiTNF $\alpha$ ] blockers, interleukin-1 or -6 inhibitors, B-cell depleting antibodies, selective costimulation inhibitors, and others). ${ }^{2}$ In case of DMARD failure or loss of efficacy, 
biological agents offer an option to slow or stop disease activity. ${ }^{3}$ However, the frequency of patients who do not tolerate or do not respond sufficiently to TNF $\alpha$ blockers within the first year is remarkable: the rate of patients experiencing inadequate treatment response in large randomized clinical trials varies between $21 \%-58 \% .^{4-11}$

Therapy with rituximab (MabThera ${ }^{\circledR}$ ), a chimeric monoclonal antibody specific for the unique cell surface marker CD20 - which is found on B-cells - is one of the treatment options for optimizing RA therapy. ${ }^{5,6,12-14}$

Since the approval of rituximab, the rheumatologist in daily routine has the option to switch to B-cell-targeted therapy instead of using a second TNF $\alpha$ blocker after treatment failure of the first TNF $\alpha$-inhibitor. A Swiss cohort study was the first to directly compare rituximab with TNF $\alpha$ blockers in clinical routine. ${ }^{15,16}$ Its results suggest that in patients with persistent active disease despite anti-TNF therapy, switching to rituximab may be more effective than cycling to an alternative anti-TNF agent.

The present German noninterventional cohort study was designed similarly to the Swiss study. ${ }^{16}$ However, patients with at least one TNF $\alpha$ blocker failure were included in the Swiss cohort study, while the present study investigated the potential superiority of rituximab after failure of only one TNF $\alpha$ blocker.

\section{Material and methods}

This noninterventional study was a multicenter, open-label, retrospective, comparative, postmarketing, observational study in Germany.

\section{Patients}

Patients were included after written informed consent was obtained according to the study protocol, which was approved by the Ethics Committee of the Otto-von-Guericke University of Magdeburg (Magdeburg, Germany). Eligible patients had to have an oral dose of corticosteroids up to a methylprednisolone equivalent $<20 \mathrm{mg}$ per day. Only patients who received rituximab (two 1 -g doses) were included in cohort one (rituximab cohort), and only patients who received a second TNF $\alpha$ blocker (etanercept, adalimumab, or infliximab) were included in cohort two (TNF $\alpha$ blocker cohort). Data of patients who had participated in interventional studies during the recorded period or had received biologic therapies other than TNF $\alpha$ blocker treatment were not included in the documentation within this noninterventional study.

Data from 247 patients in 45 study centers throughout Germany (two to 20 patients per center, median of four patients) were documented for this noninterventional study. Safety data were available for all 247 patients, as all of them received at least one dose of rituximab or TNF $\alpha$ blocker within the documentation period. Evaluable efficacy data were available for 196 patients. In this analysis set, only patients with a baseline Disease Activity Score-28 (DAS28) value of $\geq 3.2$ points, (ie, patients with active RA) were included; they were treated and observed for about 6 months, and had valid DAS28 values at baseline and at the end of observation. Subgroup analyses were performed with patients who were seropositive for rheumatoid factor (RF) or anti-cyclic citrullinated peptide (anti-CCP) antibodies or both biomarkers. Biomarkers were determined using commercially available kits.

\section{Evaluation of clinical outcome}

All efficacy, safety, and further variables (eg, demography) were analyzed and interpreted in an exploratory manner. DAS28 was calculated as described by Prevoo et al. ${ }^{17}$ European League Against Rheumatism (EULAR) response rates were calculated as the proportion of patients who achieved no response $(\triangle \mathrm{DAS} 28 \leq 0.6$ or $\triangle \mathrm{DAS} 28>0.6-1.2$ and DAS28 $>5.1$ at endpoint), moderate response $(\triangle \mathrm{DAS} 28>0.6-1.2$ and DAS28 $\leq 5.1$ at endpoint or $\Delta$ DAS28 $>1.2$ and DAS2 $>3.2$ at endpoint), or good response $(\triangle \mathrm{DAS} 28>1.2$ and DAS28 $\leq 3.2$ at endpoint), and compared between cohort one and cohort two. ${ }^{18}$ Pain was assessed using a visual analog scale ranging from zero to ten. The Health Assessment Questionnaire was used to assess the patients' physical ability according to eight areas of daily activities. ${ }^{19}$

\section{Statistical analysis}

Patient outcomes (baseline, 3 months, and end of observation) were summarized for continuous variables stating the mean, standard deviation, median, and range, and for categorical variables reporting the total and relative frequency. Pre-post comparisons were calculated for changes from baseline to end of observation as applicable, using 95\% confidence intervals. Cohort comparisons were calculated using $t$-tests for continuous variables and chi-squared tests for categorical variables. DAS28 at 6 months was defined as the primary efficacy endpoint; all other comparisons were interpreted in an exploratory manner.

\section{Results}

More female $(77.6 \%)$ than male $(22.4 \%)$ patients with a mean age of about 57 years gave their consent to provide 
their clinical data for this noninterventional study. Ninety patients had been treated with rituximab and 106 with a second TNF $\alpha$ blocker. Comorbidity was present in $76.5 \%$ of the total population, most frequently musculoskeletal and cardiovascular disorders. However, the comorbidities, like other patient characteristics, were fairly equally distributed between both cohorts. An overview of the main demographic, clinical, and baseline characteristics is given in Table 1.

The median observation plus treatment period was 197 days in the rituximab cohort and 189 days in the TNF $\alpha$ cohort. The most frequent reason for change of the first TNF $\alpha$

Table I Demographic and disease-related characteristics at start of documentation (baseline)

\begin{tabular}{|c|c|c|}
\hline Characteristics & $\begin{array}{l}\text { Rituximab } \\
\mathrm{n}=90\end{array}$ & $\begin{array}{l}\text { TNF } \alpha \text { blocker } \\
\mathrm{n}=106\end{array}$ \\
\hline Gender, male (n [\%]) & $24(26.7)$ & $20(18.9)$ \\
\hline Age, years (median [range]) & $57(27-79)$ & $58(2 I-83)$ \\
\hline $\begin{array}{l}\text { Duration of disease at inclusion, } \\
\text { years (median [range]) }\end{array}$ & $7.3(0.9-30.6)$ & $8.4(0.2-38.3)$ \\
\hline \multicolumn{3}{|l|}{ Seropositivity (n [\%]) } \\
\hline RF & $67(74.4)$ & $89(84.0)$ \\
\hline Anti-CCP & $68(75.6)$ & $64(60.4)$ \\
\hline RF or anti-CCP & $79(87.8)$ & $91(85.8)$ \\
\hline $\mathrm{RF}$ and anti-CCP & $56(62.2)$ & $62(58.5)$ \\
\hline Neither RF nor anti-CCP & $10(11.1)$ & $13(12.3)$ \\
\hline Missing & $\mathrm{I}(\mathrm{I} . \mathrm{I})$ & $2(1.8)$ \\
\hline \multicolumn{3}{|l|}{$\operatorname{DMARDs}^{\dagger}(\mathrm{n}[\%])$} \\
\hline Methotrexate & $42(46.7)$ & $56(52.8)$ \\
\hline Leflunomide & $26(28.9)$ & $28(26.4)$ \\
\hline Sulfasalazine & $4(4.4)$ & $3(2.8)$ \\
\hline Antimalarials & $\mathrm{I}(\mathrm{I} . \mathrm{I})$ & $3(2.8)$ \\
\hline Other DMARD & $4(4.4)$ & $2(1.9)$ \\
\hline No DMARD & $5(5.6)$ & $5(4.7)$ \\
\hline Missing & $15(16.7)$ & $19(17.9)$ \\
\hline Oral glucocorticoids ${ }^{\ddagger}$ (n [\%]) & $79(87.8)$ & $88(83.0)$ \\
\hline \multicolumn{3}{|l|}{ Prior TNF $\alpha$ (n [\%]) } \\
\hline Etanercept & $39(43.3)$ & $45(42.5)$ \\
\hline Adalimumab & $43(47.8)$ & $42(39.6)$ \\
\hline Infliximab & $5(5.6)$ & $18(17.0)$ \\
\hline Missing & $3(3.3)$ & I (0.9) \\
\hline $\begin{array}{l}\text { C-reactive protein, } \mathrm{mg} / \mathrm{dL} \\
(\text { mean } \pm \text { SEM) }\end{array}$ & $5.7 \pm 0.9$ & $4.8 \pm 0.7$ \\
\hline $\begin{array}{l}\text { Erythrocyte sedimentation rate, } \\
\mathrm{mm} / \mathrm{hour}(\mathrm{m} \pm \mathrm{SEM})\end{array}$ & $36.4 \pm 2.2$ & $34.8 \pm 2.2$ \\
\hline DAS28 $(m \pm S E M)$ & $5.6 \pm 0.1$ & $5.4 \pm 0.1$ \\
\hline Tender joint count $(\mathrm{m} \pm \mathrm{SEM})$ & $10.3 \pm 0.7$ & $8.9 \pm 0.5$ \\
\hline Swollen joint count ( $m \pm$ SEM) & $7.8 \pm 0.6$ & $7.2 \pm 0.5$ \\
\hline $\begin{array}{l}\text { Health assessment questionnaire, } \\
\text { total score }(m \pm S E M)\end{array}$ & $1.8 \pm 0.1$ & $1.6 \pm 0.2$ \\
\hline
\end{tabular}

Notes: $₫ 7.6 \%$ of patients (rituximab: $5.5 \%$, second tumor necrosis factor- $\alpha$ : $9.4 \%$ ) were treated with combinations of disease-modifying antirheumatic drugs at baseline; ‡median daily dose in methylprednisolone equivalent - rituximab group: $5 \mathrm{mg}$, tumor necrosis factor- $\alpha$ group: $7.5 \mathrm{mg}$.

Abbreviations: CCP, cyclic citrullinated peptide; DAS28, Disease Activity Score-28; DMARD, disease-modifying antirheumatic drug; RF, rheumatoid factor; SEM, standard error of mean; TNF $\alpha$, tumor necrosis factor- $\alpha$. therapy was inadequate response in $79.1 \%$ of all patients and intolerable side effects in $11.2 \%$.

Almost half of the patients $(45.6 \%)$ were treated with two rituximab infusions at baseline without a second course during the observation period; 16 patients $(17.8 \%)$ needed one or two further infusions after 3 months, and 42 patients (46.7\%) needed one or two further infusions at 6 months. The majority of patients in the rituximab cohort $(83.3 \%)$ were treated with rituximab together with methylprednisolone (median of $5 \mathrm{mg}$ in the rituximab cohort and $7.5 \mathrm{mg}$ in the $\mathrm{TNF} \alpha$ cohort) plus analgesics plus antihistamines as indicated by the manufacturer. In the TNF $\alpha$ cohort, 47 (44.3\%) patients received etanercept (50 mg subcutaneously weekly), 43 (40.6\%) patients received adalimumab (40 mg subcutaneously every 2 weeks) and $16(15.1 \%)$ patients were treated with infliximab (intravenous dose of $3 \mathrm{mg} / \mathrm{kg}$ at 0 weeks, 2 weeks, and 6 weeks, and thereafter every 8 weeks) as the second TNF $\alpha$ blocker.

Frequency and dosage of DMARD intake fluctuated slightly during the observational period. At baseline, $83.3 \%$ of patients treated with rituximab and $82.1 \%$ of patients treated with TNF $\alpha$ blockers received DMARDs concomitantly. These numbers decreased to $68.9 \%$ and $62.3 \%$ after 3 months and increased again to $81.1 \%$ and $77.4 \%$ after 6 months. Methotrexate was taken by $38 \%-48 \%$ of the patients in both cohorts throughout the observational period. Here, the frequency of patients with concomitant methotrexate therapy also decreased slightly at 3 months and increased again at the end of observation.

\section{Efficacy results}

Although improvement was more pronounced under rituximab therapy compared to TNF $\alpha$ treatment in all variables, a statistically significant difference in the total population was only observed in the DAS28 total score (Figure 1). Interestingly, the higher improvements in the rituximab cohort were only seen in patients seropositive for RF and/or anti-CCP, but not in seronegative patients.

An additional analysis investigated the influence of the inadequate first TNF $\alpha$ blocker on the outcome of the switch to rituximab or a second TNF $\alpha$ blocker (Table 2). If patients were pretreated with etanercept, marked cohort differences were seen in the total cohort as well as in all subgroups according to seropositivity, although the DAS28 changes were at a somewhat lower level compared to the total population (Table 2), especially in the TNF $\alpha$ subgroup. Significant cohort differences were already found at 3 months. In contrast, pretreatment with adalimumab was 


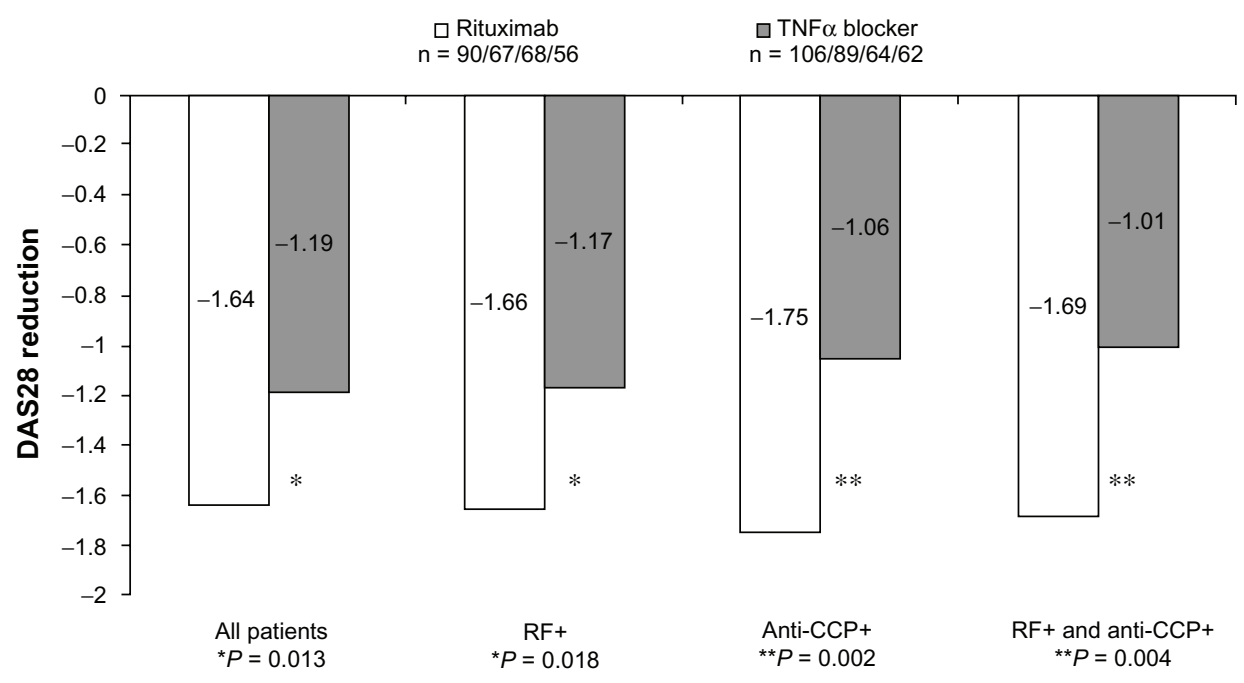

Figure I Change in mean disease activity score-28 values between endpoint and baseline in all patients and subgroups.

Abbreviations: $\mathrm{CCP}+$, seropositive for cyclic citrullinated peptide; RF+, seropositive for rheumatoid factor; TNF $\alpha$, tumor necrosis factor- $\alpha$.

associated with an increased efficacy of rituximab, especially in anti-CCP-positive patients, but had no influence on the efficacy of the second TNF $\alpha$ blocker. The number of patients in the subgroup treated with infliximab was quite small and imbalanced between the two cohorts, and insufficient for subgroup analyses. The available data for all patients show no relevant differences between the two cohorts after pretreatment with infliximab.

Comparisons of both cohorts regarding changes in tender joint counts (Figure 2 and Table 3) between

Table 2 Efficacy results depending on the first tumor necrosis factor- $\alpha$ inhibitor and seropositivity for rheumatoid factor and anticyclic citrullinated peptide: Disease Activity Score-28 change between baseline, 3 months, and 6 months

\begin{tabular}{|c|c|c|c|c|c|c|c|}
\hline \multirow[t]{2}{*}{ Previous TNF $\alpha$} & \multirow[t]{2}{*}{ Subgroup } & \multirow[t]{2}{*}{ Month } & \multicolumn{2}{|c|}{ Rituximab } & \multicolumn{2}{|c|}{ TNF $\alpha$} & \multirow[t]{2}{*}{$P$ value* } \\
\hline & & & $\mathbf{n}$ & Mean $(95 \% \mathrm{Cl})$ & $\mathbf{n}$ & Mean $(95 \% \mathrm{Cl})$ & \\
\hline \multirow[t]{8}{*}{ Etanercept } & \multirow[t]{2}{*}{ All patients } & 3 & 28 & $-1.29(-1.62 ;-0.96)$ & 30 & $-0.76(-1.06 ;-0.47)$ & 0.017 \\
\hline & & 6 & 39 & $-1.53(-1.98 ;-1.08)$ & 45 & $-0.96(-1.30 ;-0.62)$ & 0.042 \\
\hline & \multirow[t]{2}{*}{$\mathrm{RF}+$} & 3 & 22 & $-1.31(-1.65 ;-0.96)$ & 25 & $-0.72(-1.06 ;-0.38)$ & 0.016 \\
\hline & & 6 & 32 & $-1.54(-2.04 ;-1.03)$ & 37 & $-0.88(-1.27 ;-0.50)$ & 0.037 \\
\hline & \multirow[t]{2}{*}{ Anti-CCP+ } & 3 & 21 & $-1.23(-1.59 ;-0.87)$ & 19 & $-0.51(-0.88 ;-0.13)$ & 0.006 \\
\hline & & 6 & 31 & $-1.58(-2.11 ;-1.05)$ & 26 & $-0.81(-1.29 ;-0.32)$ & 0.035 \\
\hline & \multirow{2}{*}{$\mathrm{RF}+$ and anti-CCP+ } & 3 & 18 & $-1.27(-1.68 ;-0.87)$ & 19 & $-0.51(-0.88 ;-0.13)$ & 0.006 \\
\hline & & 6 & 27 & $-1.56(-2.12 ;-1.00)$ & 26 & $-0.81(-1.29 ;-0.32)$ & 0.042 \\
\hline \multirow[t]{8}{*}{ Adalimumab } & \multirow[t]{2}{*}{ All patients } & 3 & 35 & $-1.34(-1.79 ;-0.90)$ & 35 & $-1.21(-1.66 ;-0.76)$ & 0.673 \\
\hline & & 6 & 43 & $-1.70(-2.10 ;-1.30)$ & 42 & $-1.33(-1.72 ;-0.93)$ & 0.189 \\
\hline & \multirow[t]{2}{*}{$\mathrm{RF}+$} & 3 & 24 & $-1.52(-2.01 ;-1.04)$ & 30 & $-1.12(-1.63 ;-0.61)$ & 0.252 \\
\hline & & 6 & 29 & $-1.78(-2.27 ;-1.29)$ & 37 & $-1.26(-1.69 ;-0.82)$ & 0.109 \\
\hline & \multirow[t]{2}{*}{ Anti-CCP+ } & 3 & 26 & $-1.64(-2.18 ;-1.11)$ & 21 & $-0.88(-1.57 ;-0.19)$ & 0.073 \\
\hline & & 6 & 33 & $-1.95(-2.4 \mid ;-1.50)$ & 26 & $-1.08(-1.49 ;-0.68)$ & 0.006 \\
\hline & \multirow[t]{2}{*}{$\mathrm{RF}+$ and anti-CCP+ } & 3 & 21 & $-1.60(-2.14 ;-1.05)$ & 20 & $-0.77(-1.45 ;-0.08)$ & 0.053 \\
\hline & & 6 & 25 & $-1.86(-2.42 ;-1.29)$ & 25 & $-1.00(-1.38 ;-0.62)$ & 0.013 \\
\hline \multirow[t]{8}{*}{ Infliximab } & \multirow[t]{2}{*}{ All patients } & 3 & 5 & $-1.17(-2.30 ;-0.04)$ & 13 & $-1.73(-2.34 ;-1.13)$ & 0.292 \\
\hline & & 6 & 5 & $-1.36(-2.12 ;-0.60)$ & 18 & $-1.53(-2.11 ;-0.96)$ & 0.756 \\
\hline & \multirow[t]{2}{*}{$\mathrm{RF}+$} & 3 & 5 & $-1.17(-2.30 ;-0.04)$ & 10 & $-2.09(-2.47 ;-1.72)$ & 0.026 \\
\hline & & 6 & 4 & $-1.45(-2.5 \mathrm{I} ;-0.39)$ & 14 & $-1.82(-2.32 ;-1.32)$ & 0.440 \\
\hline & \multirow[t]{2}{*}{ Anti-CCP+ } & 3 & 4 & $-0.94(-2.34 ;+0.45)$ & 7 & $-1.99(-2.42 ;-1.57)$ & 0.026 \\
\hline & & 6 & 4 & $-1.45(-2.5 \mathrm{I} ;-0.39)$ & 11 & $-1.75(-2.33 ;-1.17)$ & 0.542 \\
\hline & \multirow[t]{2}{*}{$\mathrm{RF}+$ and anti-CCP+ } & 3 & 4 & $-0.94(-2.34 ;+0.45)$ & 7 & $-1.99(-2.42 ;-1.57)$ & 0.026 \\
\hline & & 6 & 4 & $-1.45(-2.5 \mathrm{I} ;-0.39)$ & 10 & $-1.74(-2.39 ;-1.10)$ & 0.570 \\
\hline
\end{tabular}

Notes: $* P$ values associated with $t$-test for comparison of the two cohorts. All $P$ values are descriptive information.

Abbreviations: $\mathrm{CCP}+$, seropositive for cyclic citrullinated peptide; $\mathrm{Cl}$, confidence interval; $\mathrm{RF}+$, seropositive for rheumatoid factor; $\mathrm{TNF} \alpha$, tumor necrosis factor- $\alpha$. 


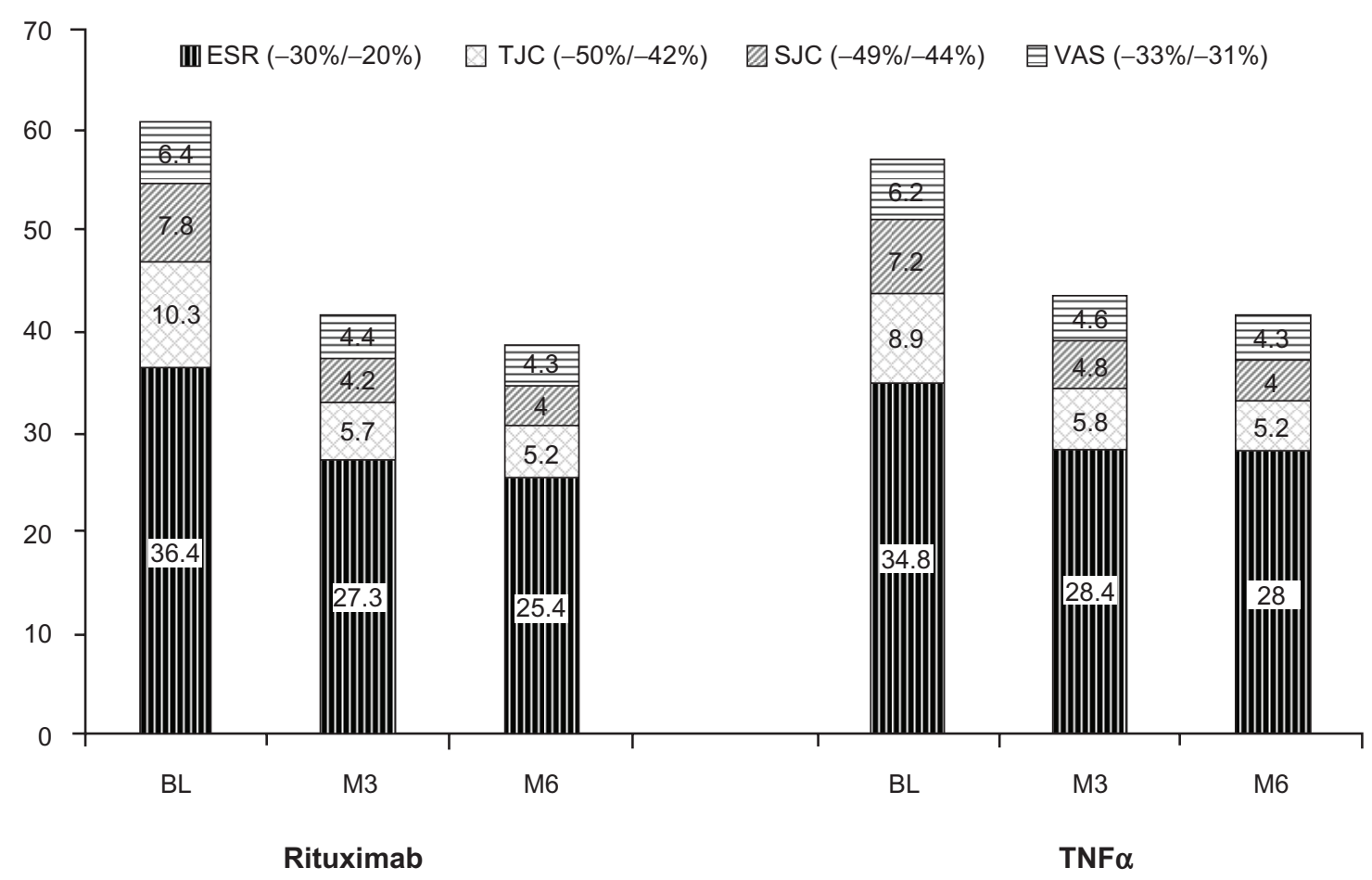

Figure 2 The mean absolute values of erythrocyte sedimentation rate, tender joint counts, swollen joint counts, and pain visual analog scale at baseline, 3 months posttreatment, and 6 months posttreatment.

Note: The average percent improvement between baseline and 6 months posttreatment for rituximab cohort and tumor necrosis factor- $\alpha$, respectively, are included in the legend section (change of group means).

Abbreviations: BL, baseline; ESR, erythrocyte sedimentation rate; M3, 3 months posttreatment; M6, 6 months posttreatment; SJC, swollen joint counts; TJC, tender joint counts; TNF $\alpha$, tumor necrosis factor- $\alpha$; VAS, visual analog scale.

baseline and end of observation revealed differences only in the subgroups of anti-CCP-positive patients $(-5.28$ [95\% confidence interval: $-6.78 ;-3.79]$ versus -3.06 [95\% confidence interval: $-4.28 ;-1.85], P=0.024$ ) and patients seropositive for both anti-CCP and RF $(-5.49$ [95\% confidence interval: $-7.21 ;-3.77]$ versus $-2.85[95 \%$ confidence interval: $-4.05 ;-1.66], P=0.013)$.
For erythrocyte sedimentation rate, cohorts did not differ at the end of observation (Figure 2); however, at 3 months there was a larger decrease under rituximab compared to the TNF $\alpha$ cohort $(-11.2[95 \%$ confidence interval: $-15.61 ;-6.79]$ versus $-4.03[95 \%$ confidence interval:-9.10; 1.05], $P=0.037)$. A similar difference between both cohorts was observed in the RF-positive subgroup

Table 3 Efficacy results: change from baseline to end of observation (I96 patients)

\begin{tabular}{|c|c|c|c|c|c|}
\hline \multirow[t]{2}{*}{ Efficacy variable } & \multicolumn{2}{|c|}{ Rituximab } & \multicolumn{2}{|c|}{ TNF $\alpha$ blocker } & \multirow[t]{2}{*}{$P$ value* } \\
\hline & $\mathbf{n}$ & Mean $(95 \% \mathrm{Cl})$ & $\mathbf{n}$ & Mean $(95 \% \mathrm{Cl})$ & \\
\hline \multicolumn{6}{|l|}{ DAS28 } \\
\hline All patients & 90 & $-1.64(-1.92 ;-1.36)$ & 106 & $-1.19(-1.42 ;-0.96)$ & 0.013 \\
\hline Seropositive for RF & 67 & $-1.66(-1.98 ;-1.34)$ & 89 & $-1.17(-1.43 ;-0.91)$ & 0.018 \\
\hline Seropositive for CCP & 68 & $-1.75(-2.07 ;-1.43)$ & 64 & $-1.06(-1.34 ;-0.78)$ & 0.002 \\
\hline Seropositive for RF and CCP & 56 & $-1.69(-2.05 ;-1.32)$ & 62 & $-1.01(-1.29 ;-0.73)$ & 0.004 \\
\hline Not seropositive for RF or CCP & 10 & $-1.07(-2.08 ;-0.06)$ & 13 & $-0.93(-1.58 ;-0.28)$ & 0.791 \\
\hline Tender joint count & 89 & $-5.08(-6.43 ;-3.73)$ & 105 & $-3.66(-4.60 ;-2.72)$ & 0.088 \\
\hline Swollen joint count & 89 & $-3.83(-5.00 ;-2.67)$ & 105 & $-3.19(-4.13 ;-2.25)$ & 0.390 \\
\hline Visual analog scale & 86 & $-2.15(-2.62 ;-1.67)$ & 93 & $-1.99(-2.49 ;-1.48)$ & 0.646 \\
\hline Erythrocyte sedimentation rate, $\mathrm{mm} /$ hour & 88 & $-10.5 \mid(-14.85 ;-6.17)$ & 103 & $-6.81(-10.90 ;-2.72)$ & 0.220 \\
\hline C-reactive protein, $\mathrm{mg} / \mathrm{dL}$ & 72 & $-2.37(-3.98 ;-0.77)$ & 83 & $-0.90(-2.34 ;+0.55)$ & 0.173 \\
\hline Health assessment questionnaire & 26 & $-0.13(-0.31 ;+0.05)$ & 21 & $-0.29(-0.52 ;-0.06)$ & 0.257 \\
\hline
\end{tabular}

Notes: *P values associated with $t$-test for comparison of the two cohorts. All $P$ values except for DAS28 "all patients" are descriptive information.

Abbreviations: CCP, cyclic citrullinated peptide; $\mathrm{Cl}$, confidence interval; DAS28, Disease Activity Score-28; RF, rheumatoid factor; TNF $\alpha$, tumor necrosis factor- $\alpha$. 
$(-12.8$ [95\% confidence interval: $-17.96 ;-7.64]$ versus -4.52 [95\% confidence interval: $-10.48 ; 1.45], P=0.038)$, but not in the anti-CCP-positive subgroup (-9.69 [95\% confidence interval: $-14.88 ;-4.49]$ versus -4.51 [95\% confidence interval: $-11.71 ; 2.69], P=0.239)$.

No cohort differences were found in other efficacy measures (swollen joint count, pain visual analog scale, C-reactive protein, Health Assessment Questionnaire). Data for swollen joint count and pain visual analog scale are presented in Figure 2.

In the rituximab cohort, $30.0 \%(\mathrm{n}=27)$ of the patients showed good EULAR response, $47.8 \%(n=43)$ of the patients showed moderate response, and $22.2 \%(n=20)$ of the patients showed no response. In the TNF $\alpha$ blocker cohort, the proportion of patients that showed good, moderate, or no response was $15.1 \%(\mathrm{n}=16), 50.0 \%(\mathrm{n}=53)$, and $34.9 \%$ $(\mathrm{n}=37)$, respectively. The cohort difference $(P=0.022$, chisquared test) was mainly due to a larger number of patients with good EULAR response $(30.0 \%$ versus $15.1 \%)$ and a lower number of patients with no response in the rituximab cohort (22.2\% versus 34.9\%) (Figure 3 ). For the RF-positive patients, the frequency distribution of response status was different between both cohorts $(P=0.023$, chi-squared test).
Furthermore, EULAR response was more favorable for rituximab than for the second TNF $\alpha$ blocker in the subgroup of anti-CCP-positive patients $(P=0.003$, chi-squared test).

\section{Safety results}

Of the 247 patients available for safety analysis, seven $(5.6 \%$ of 124$)$ patients in the rituximab and five (4.1\% of 123$)$ patients in the TNF $\alpha$ blocker cohort suffered from at least one adverse drug reaction during the observation period. In total, 15 adverse drug reactions with a possible or definite relationship to the biologics occurred in the rituximab cohort, and six occurred in the TNF $\alpha$ cohort. With one exception (sinusitis), all adverse drug reactions were reported in female patients. Most frequently, patients developed skin disorders (in three patients of each cohort).

Infusion reactions occurred in three patients treated with rituximab; infusion was interrupted in one patient receiving rituximab (facial hypoesthesia of mild intensity). In another patient, the medication was stopped due to a moderate increase in liver function parameters. The third patient with infusion reactions suffered from infection, generalized pruritus, musculoskeletal pain, urticaria, eye swelling, and fatigue.

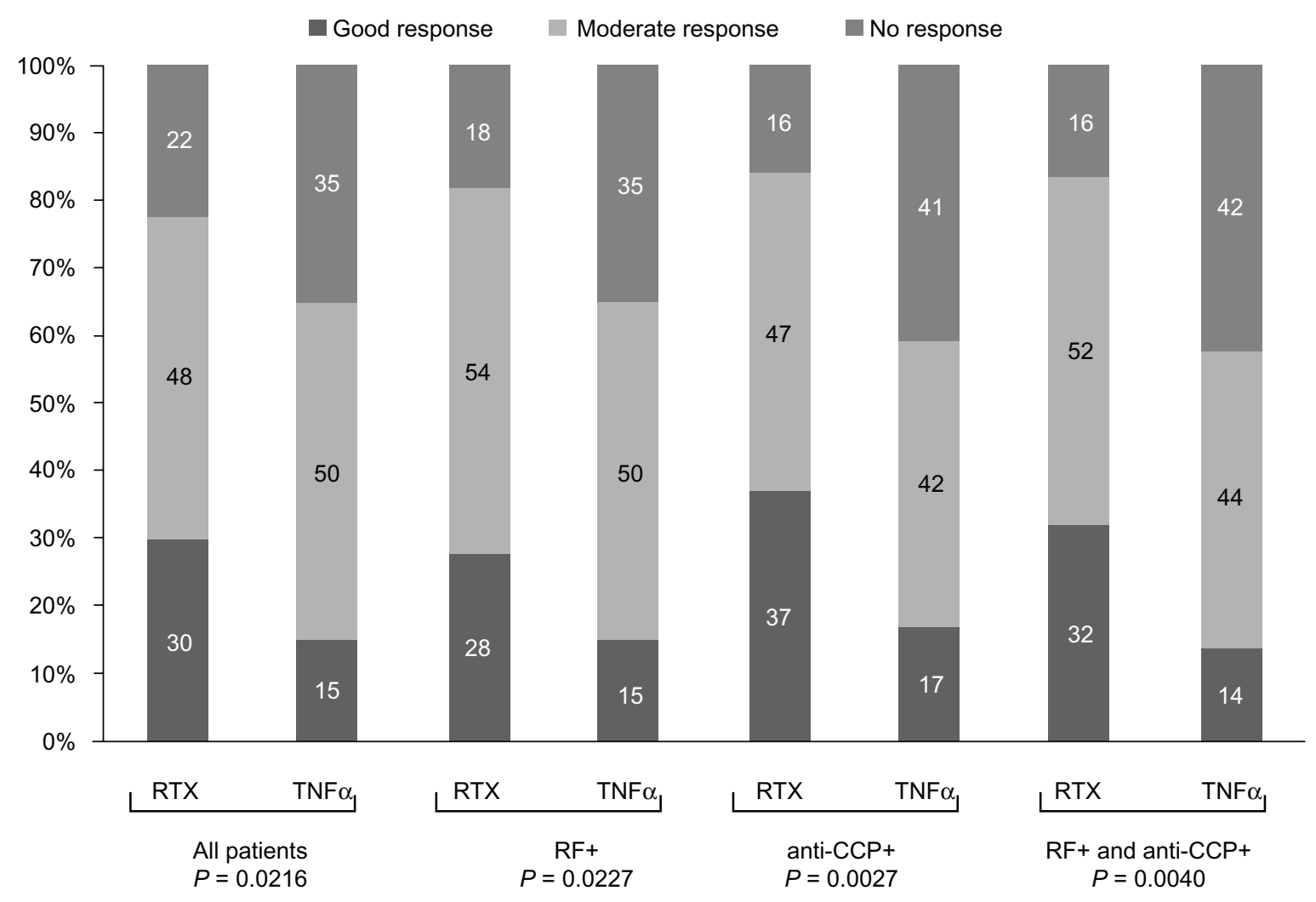

Figure 3 European league against Rheumatism response at observation endpoint in all groups.

Abbreviations: CCP+, seropositive for cyclic citrullinated peptide; RF+, seropositive for rheumatoid factor; RTX, rituximab cohort; TNFa, tumor necrosis factor- $\alpha$ cohort. 
The number of adverse drug reactions documented was similar in both cohorts. In general, all were single incidents with no accumulation in a certain class of side effects. Only one patient treated with rituximab experienced an adverse drug reaction of severe intensity (nail dystrophy, dehydration, and anemia). All other reactions were of mild to moderate intensity and no action was taken with respect to the medication. In two patients, the outcome of the adverse drug reaction was reported as "unchanged" (one in either cohort); in all other patients the outcome was reported as "recovered." No deaths or serious adverse reactions were reported during this observational study.

\section{Discussion}

Altogether, the results of the efficacy analysis in RA patients with one TNF $\alpha$ treatment failure were in favor of treatment with rituximab (cohort one) rather than treatment with a second TNF $\alpha$ blocker (cohort two). Significant cohort differences were seen in the improvement of DAS28, the primary efficacy endpoint in this study. This difference between the two groups (rituximab versus TNF $\alpha$ ) was even more pronounced when patients were seropositive for anti-CCP antibodies as well as both RF and anti-CCP antibodies. For anti-CCP positive patients, cohort differences could already be seen after 3 months, indicating a faster onset of action of rituximab in this subgroup. Differences in tender joint counts at the end of observation were noted only in the subgroups of anti-CCP-positive patients. According to EULAR criteria, more patients showed good response and less patients showed no response in the rituximab cohort as compared to the TNF $\alpha$ blocker cohort. Again, these cohort differences were more pronounced in the RF-positive patients and especially in the anti-CCP-positive patients.

The results from this noninterventional study investigating RA treatment in routine practice confirm those of placebo-controlled clinical studies that have already proven that rituximab is effective in reducing RA disease activity in patients with prior TNF $\alpha$ blocker failure. ${ }^{5,20}$ The results from this retrospective investigation extend the experience of the small prospective Swiss cohort study, which showed superior treatment outcome when patients with inadequate response to at least one anti-TNF agent were switched to rituximab compared to an alternative TNF $\alpha$ therapy ${ }^{15}$ Changes in DAS28 were of similar magnitude for rituximab in both cohort trials ( -1.61 in the Swiss study versus -1.64 in the current study), but slightly better for the second TNF $\alpha$ treatment in the current study ( -1.19 versus -0.98 in the Swiss study). As most RA patients in the Swiss study were RF-positive and CCP antibody was not assessed at that time, conclusion on the role of these potential biomarkers could not be made. However, rituximab efficacy could be demonstrated both in patients receiving at least one $\mathrm{TNF} \alpha$-blocker.

A recent study investigating the effects of seropositivity to $\mathrm{RF}$ and anti-CCP found reduced response to TNF $\alpha$ blockers in seropositive patients as compared to seronegative for both RF and anti-CCP. ${ }^{21}$ This result could not be confirmed by the current data (Table 3), which show stronger improvements in both cohorts in patients seropositive for RF and especially for anti-CCP compared to seronegative patients; however, the number of the latter subgroup was very small. In addition, the patients in the English study had a more advanced disease. Other studies focusing on the efficacy of rituximab showed that RF positivity, but not anti-CCP positivity, is predictive for rituximab efficacy. ${ }^{22,23}$ Enhanced efficacy of rituximab in RF-positive versus RF-negative patients could already be shown in the IMAGE (A Study to Evaluate Rituximab in Combination With Methotrexate in Methotrexate-Naïve Patients With Active RA) study. ${ }^{24} \mathrm{CCP}$ antibodies were not addressed in this study. Likewise in the RABBIT (RA - Observation of Biologic Therapy) register, response rates were better in RF-positive patients than in RF-negative patients receiving rituximab; a similar but smaller effect was observed in the anti-CCP-positive versus anti-CCP-negative patients. ${ }^{25}$ Although RF positivity was predictive for efficacy of rituximab in this trial, the differences between both cohorts were largest in the subgroup of anti-CCP-positive patients. However, there was an overlap in RF and anti-CCP positivity: $62 \%$ of the patients in the rituximab cohort were positive for both biomarkers. Combined with the results from the present cohort study, these findings provide clear evidence that treatment with rituximab may be more effective than a second-line biological therapy with the TNF $\alpha$ blockers etanercept, adalimumab, or infliximab. In particular, the results of the anti-CCP-positive subgroup analyses in this study may indicate how to better predict treatment response when selecting the appropriate treatment option in clinical routine, as there still seems to be the need for personalized medicine in RA. ${ }^{26}$ However, this does not mean that application of rituximab in RF-negative and antiCCP-negative patients should be avoided. The number of seronegative patients was too small in the current study to compare both cohorts.

\section{Conclusion}

The conclusions from this study are limited due to its design as a noninterventional trial. Observational data was collected 
retrospectively from two cohorts that were treated either with rituximab or a second $\mathrm{TNF} \alpha$ blocker. Treatments were not randomized and no information was available as to why patients were treated with either therapy. Therefore, confounding factors cannot be excluded which might have contributed to the differences in efficacy described above. However, there were no structural differences between the two cohorts in patient characteristics and baseline values of efficacy measures. In addition, no such differences could be detected between patients analyzed and those $21.6 \%$ of patients who were excluded from the statistical analysis. The consistency between the results of the current study and those of the Swiss cohort trial as well as of those from double-blind trials are considered in favor of valid results of this study. ${ }^{15,5,20}$

The results of this noninterventional, retrospective cohort study indicate that treatment with rituximab is superior to a second TNF $\alpha$ blocker therapy in RA patients who did not respond to a previous TNF $\alpha$ blocker in terms of clinically significant improvement of disease activity as measured by the DAS28 score. An even stronger difference between cohorts was found in the subgroup of patients seropositive for anti-CCP and for both RF and anti-CCP. Rituximab treatment was compared to the general strategy of cycling to a second TNF $\alpha$ blocker (eg, etanercept, adalimumab, or infliximab); however, rituximab was not compared to every single compound. Other TNF $\alpha$ inhibitors that were not included in this study may show a different outcome. In agreement with previous publications, the current study showed that anti-CCP positivity, in particular, could be a useful predictive biomarker for rituximab in patients with prior TNF $\alpha$ blocker treatment failure. Further attention should be given to concomitant therapies such as other DMARDs potentially influencing the response to biologics in different ways.

\section{Acknowledgments}

The authors thank Dr F Meister (ReSearch Pharmaceutical Services Inc, Nuremberg, Germany) for editorial assistance and publication coordination.

\section{Disclosure}

This noninterventional study was funded by Roche Pharma AG, Grenzach-Wyhlen, Germany.

\section{References}

1. Strand V, Khanna D. The impact of rheumatoid arthritis and treatment on patients' lives. Clin Exp Rheumatol. 2010;28(3 Suppl 59):S32-S40.

2. McInnes IB, O'Dell JR. State-of-the-art: rheumatoid arthritis. Ann Rheum Dis. 2010;69(11):1898-1906.
3. Rath T, Rubbert A. Drug combinations with methotrexate to treat rheumatoid arthritis. Clin Exp Rheumatol. 2010;28(5 Suppl 61): S52-S57.

4. Redlich K, Schett G, Steiner G, Hayer S, Wagner EF, Smolen JS. Rheumatoid arthritis therapy after tumor necrosis factor and interleukin-1 blockade. Arthritis Rheum. 2003;48(12):3308-3319.

5. Cohen SB, Emery P, Greenwald MW, et al. Rituximab for rheumatoid arthritis refractory to anti-tumor necrosis factor therapy: results of a multicenter, randomized, double-blind, placebo-controlled, phase III trial evaluating primary efficacy and safety at twenty-four weeks. Arthritis Rheum. 2006;54(9):2793-2806.

6. Keystone E, Burmester GR, Furie R, et al. Improvement in patientreported outcomes in a rituximab trial in patients with severe rheumatoid arthritis refractory to anti-tumor necrosis factor therapy. Arthritis Rheum. 2008;59(6):785-793.

7. Keystone EC, Schiff MH, Kremer JM, et al. Once-weekly administration of $50 \mathrm{mg}$ etanercept in patients with active rheumatoid arthritis: results of a multicenter, randomized, double-blind, placebo-controlled trial. Arthritis Rheum. 2004;50(2):353-363.

8. Lipsky PE, van der Heijde DM, St Clair EW, et al. Infliximab and methotrexate in the treatment of rheumatoid arthritis. $N$ Engl J Med. 2000;343(22):1594-1602.

9. Seymour HE, Worsley A, Smith JM, Thomas SH. Anti-TNF agents for rheumatoid arthritis. Br J Clin Pharmacol. 2001;51(3): 201-208.

10. Weinblatt ME, Keystone EC, Furst DE, et al. Adalimumab, a fully human anti-tumor necrosis factor $\alpha$ monoclonal antibody, for the treatment of rheumatoid arthritis in patients taking concomitant methotrexate: the ARMADA Trial. Arthritis Rheum. 2003;48(1):35-45.

11. Weinblatt ME, Kremer JM, Bankhurst AD, et al. A trial of etanercept, a recombinant tumor necrosis factor receptor: $\mathrm{Fc}$ fusion protein, in patients with rheumatoid arthritis receiving methotrexate. $N$ Engl $J$ Med. 1999;340(4):253-259.

12. Edwards JC, Szczepanski L, Szechinski J, et al. Efficacy of B-celltargeted therapy with rituximab in patients with rheumatoid arthritis. N Engl J Med. 2004;350(25):2572-2581.

13. Edwards JC, Cambridge G. Sustained improvement in rheumatoid arthritis following a protocol designed to deplete B lymphocytes. Rheumatology (Oxford). 2001;40(2):205-211.

14. Emery P, Fleischmann R, Filipowicz-Sosnowska A, et al. The efficacy and safety of rituximab in patients with active rheumatoid arthritis despite methotrexate treatment: results of a phase IIB randomized, double-blind, placebo-controlled, dose-ranging trial. Arthritis Rheum. 2006;54(5):1390-1400.

15. Finckh A, Ciurea A, Brulhart L, et al. B cell depletion may be more effective than switching to an alternative anti-tumor necrosis factor agent in rheumatoid arthritis patients with inadequate response to anti-tumor necrosis factor agents. Arthritis Rheum. 2007;56(5): $1417-1423$.

16. Finckh A, Ciurea A, Brulhart L, et al. Which subgroup of patients with rheumatoid arthritis benefits from switching to rituximab versus alternative anti-tumour necrosis factor (TNF) agents after previous failure of an anti-TNF agent? Ann Rheum Dis. 2010;69(2):387-393.

17. Prevoo ML, van't Hof MA, Kuper HH, van Leeuwen MA, van der Putte LB, van Riel PL. Modified disease activity scores that include twenty-eight-joint counts. Development and validation in a prospective longitudinal study of patients with rheumatoid arthritis. Arthritis Rheum. 1995;38(1):44-48.

18. Fransen J, van Riel PL. The Disease Activity Score and the EULAR response criteria. Clin Exp Rheumatol. 2005;23(5 Supp1 39): S93-S99.

19. Fries JF, Spitz P, Kraines RG, Holman HR. Measurement of patient outcome in arthritis. Arthritis Rheum. 1980;23(2):137-145.

20. Keystone E, Emery P, Peterfy CG, et al. Rituximab inhibits structural joint damage in patients with rheumatoid arthritis with an inadequate response to tumour necrosis factor inhibitor therapies. Ann Rheum Dis. 2009;68(2):216-221. 
21. Potter C, Hyrich KL, Tracey A, et al. Association of rheumatoid factor and anti-cyclic citrullinated peptide positivity, but not carriage of shared epitope or PTPN22 susceptibility variants, with anti-tumour necrosis factor response in rheumatoid arthritis. Ann Rheum Dis. 2009;68(1):69-74.

22. Benucci M, Manfredi M, Puttini PS, Atzeni F. Predictive factors of response to rituximab therapy in rheumatoid arthritis: what do we know today? Autoimmun Rev. 2010;9(12):801-803.

23. Quartuccio L, Fabris M, Salvin S, et al. Rheumatoid factor positivity rather than anti-CCP positivity, a lower disability and a lower number of anti-TNF agents failed are associated with response to rituximab in rheumatoid arthritis. Rheumatology (Oxford). 2009;48(12):1557-1559.
24. Tak PP, Rigby WF, Rubbert-Roth A, et al. Inhibition of joint damage and improved clinical outcomes with rituximab plus methotrexate in early active rheumatoid arthritis: the IMAGE trial. Ann Rheum Dis. 2011;70(1):39-46.

25. Strangfeld A, Eveslage M, Kekow J, et al. Effectiveness of treatment with rituximab depends on autoantibody status: results from 2 years of experience in the German biologics register RABBIT [Abstract] Arthritis Rheum. 2009;60 Suppl 10:1695.

26. Isaacs JD, Ferracioli G. The need for personalised medicine for rheumatoid arthritis. Ann Rheum Dis. 2011;70(1):4-7.

\section{Publish your work in this journal}

Biologics: Targets \& Therapy is an international, peer-reviewed journal focusing on the patho-physiological rationale for and clinical application of Biologic agents in the management of autoimmune diseases, cancers or other pathologies where a molecular target can be identified This journal is indexed on PubMed Central, CAS, EMBase, Scopus

Submit your manuscript here: http://www.dovepress.com/biologics-targets--therapy-journal

\section{Dovepress}

and the Elsevier Bibliographic databases. The manuscript management system is completely online and includes a very quick and fair peerreview system, which is all easy to use. Visit http://www.dovepress. com/testimonials.php to read real quotes from published authors. 